\title{
Protein kinase C regulates Twist1 expression via NF- $\kappa B$ in prostate cancer
}

\author{
Masaki Shiota', Akira Yokomizo', Ario Takeuchi', Eiji Kashiwagi', Takashi Dejima', \\ Junichi Inokuchi', Katsunori Tatsugami', Takeshi Uchiumi² and Masatoshi Eto' \\ 'Department of Urology, Graduate School of Medical Sciences, Kyushu University, Fukuoka, Japan \\ 2Department of Clinical Chemistry and Laboratory Medicine, Graduate School of Medical Sciences, \\ Kyushu University, Fukuoka, Japan
}

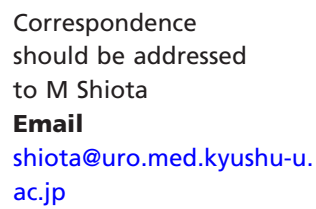

\begin{abstract}
The progression of prostate cancer to metastatic and castration-resistant disease represents a critical step. We previously showed that protein kinase C (PKC) activation followed by Twist1 and androgen receptor (AR) induction played a critical role in castration resistance, but the precise molecular mechanism remains unknown. This study aimed to elucidate the relevant molecular mechanism, focusing on NF-KB transcription factor. We examined the activity of NF-KB after PKC inhibition, and the expression of Twist1 and AR after inhibition of NF-KB in human prostate cancer cells. We also investigated the status of PKC/NF-KB after inhibition of AR signaling in cells resistant to hormonal therapy. As a result, inhibition of PKC signaling using knockdown and smallmolecule inhibition of PKC suppressed RelA activity, while blocking NF-kB suppressed Twist1 and AR expression. Conversely, inhibition of AR signaling by androgen depletion and the novel antiandrogen enzalutamide induced PKC and RelA activation, resulting in Twist1/AR induction at the transcript level. Moreover, inhibition of NF- $\mathrm{kB}$ signaling prevented enzalutamide-induced Twist1 and AR induction. Finally, NF-kB was activated in both castration-resistant and enzalutamide-resistant cells. In conclusion, NF- $\mathrm{kB}$ signaling was responsible for Twist1 upregulation by PKC in response to AR inhibition, resulting in aberrant activation of AR. NF-KB signaling thus appears to play a critical role in promoting both castration resistance and enzalutamide resistance in $\mathrm{PKC} / \mathrm{Tw}$ wist1 signaling in prostate cancer.
\end{abstract}

\section{Key Words}

- androgen receptor

- NF-kB

- protein kinase $C$

- prostate cancer

- Twist1

\section{Introduction}

Androgen deprivation therapy (ADT) is currently the gold-standard treatment for recurrent or advanced prostate cancer (Sharifi et al. 2010). Most prostate cancers are initially dependent on androgen receptor (AR) signaling for cell proliferation and cellular survival, at which point most patients respond well to ADT. However, most patients with prostate cancer eventually relapse in a castration-resistant manner during ADT, which is defined as castration-resistant prostate cancer (CRPC) (Sadar 2011). Several novel AR-targeting agents against
CRPC have recently been developed, including the nextgeneration antiandrogen enzalutamide (Ryan \& Tindall 2011, Scher et al. 2012) and the cytochrome P17 inhibitor abiraterone acetate (de Bono et al. 2011, Ryan et al. 2013). However, their therapeutic effects are modest, and novel therapeutic strategies are required to improve the prognosis in men with CRPC.

The mechanisms responsible for the development of CRPC include aberrant activation of AR under low levels of circulating androgens such as de novo androgen synthesis

Published by Bioscientifica Ltd 
(Cai \& Balk 2011), AR overexpression (Shiota et al. 2011b, Waltering et al. 2012), AR gene mutations (Waltering et al. 2012), AR co-regulators (Shiota et al. 2011a), AR activation by intracellular signal-transduction pathways (Inoue \& Ogawa 2011) and AR splice variants (Waltering et al. 2012). The transcription factor Twist1 binds to the E-box (5'-CANNTG-3') sequence to upregulate the expression of its target genes, resulting in the promotion of epithelialto-mesenchymal transition (Shiota et al. 2008). Twist1 was upregulated after androgen ablation in a mouse xenograft model (Sun et al. 2012), as well as in human prostate cancer tissues (Shiota et al. 2012a), leading to the development of CRPC and enzalutamide resistance through AR upregulation (Shiota et al. 2010, 2014a).

Similarly, PKC signaling was highly activated in CRPC specimens compared with that in hormone-naïve cancers (Inoue \& Ogawa 2011), where PKC has been implicated in both castration resistance (Inoue et al. 2006) and enzalutamide resistance (Shiota et al. 2014a). We previously reported that activation of PKC by blocking AR signaling induced Twist1 expression, leading to castration resistance and enzalutamide resistance through upregulation of AR (Shiota et al. 2014a).

Although the mechanism by which PKC regulates Twist1 expression remains unknown, Twist1 expression was affected at the transcriptional level, suggesting that transcription factors may mediate PKC-induced Twist1 induction. Several transcription factors, such as STAT3 (Lo et al. 2007, Cheng et al. 2008), hypoxia-inducible factor $1 \alpha$ (HIF-1 $\alpha$ ) (Yang et al. 2008) and NF-кB (Pham et al. 2007), have been reported to regulate Twist1 expression directly. In this study, we aimed to elucidate the signaling cascade of PKC/Twist1 and to clarify their roles in castration- and enzalutamide-resistant prostate cancer.

\section{Materials and methods}

\section{Cell culture}

Human prostate cancer LNCaP, C4-2 and 22Rv1 cells were cultured in RPMI-1640 (Invitrogen) containing 10\% fetal bovine serum. LNCaP and 22Rv1 cells were obtained from the American Type Culture Collection (Manassas, VA, USA) and authenticated by short tandem repeat (STR) analysis. LNCaP cells were used after 10-40 rounds of propagation. C4-2 cells authenticated by whole-genome and wholetranscriptome sequencing on an Illumina Genome Analyzer IIx platform (Lamoureux et al. 2011) were kindly provided by Dr Martin Gleave (Vancouver Prostate Centre, Vancouver, BC, Canada). Castration-resistant derivatives of LNCaP cells (LNCaP-CxR cells, referred to as CxR cells) were established and maintained as described previously (Shiota et al. 2010). Enzalutamide-resistant derivatives of LNCaP and C4-2 cells (LNCaP/MDV and C4-2/MDV cells) were established by long-term culture in the appropriate media containing gradually increasing concentrations of enzalutamide and maintained in media containing $50 \mu \mathrm{M}$ enzalutamide (Shiota et al. 2014b). The cell lines were maintained in a $5 \% \mathrm{CO}_{2}$ atmosphere at $37^{\circ} \mathrm{C}$.

\section{Antibodies and reagents}

Antibodies against RelA (sc-372), AR (N-20, sc-816) and Twist1 (sc-81417) were purchased from Santa Cruz Biotechnology. Antibodies against phosphorylated RelA ${ }^{\text {Ser536 }}$ (p-RelA, \#3033), phosphorylated PKC Ser660 (BII) (p-PKC; \#9371), phosphorylated STAT3 ${ }^{\text {Ser727 (p-STAT3 }}{ }^{\text {Ser727; }}$ \#9134) and STAT3 (\#4904) were purchased from Cell Signaling Technology. Anti-PKC (SAB4502356), HIF-1 $\alpha$ (HPA001275) and anti- $\beta$-actin (A3854) antibodies were obtained from Sigma-Aldrich.

\section{Transfection with small-interfering RNAs}

Double-stranded small-interfering RNA (siRNA) 25 base pair oligonucleotides were generated commercially (Invitrogen). The target sequences are listed in Supplementary Table 1 (see section on supplementary data given at the end of this article). Prostate cancer cells were transfected with siRNA using Lipofectamine 2000 (Invitrogen) according to the manufacturer's protocol.

\section{RNA isolation, reverse transcription and quantitative real-time PCR}

RNA isolation and reverse transcription were performed as described previously (Shiota et al. 2014a, 2016). Quantitative real-time PCR was performed using TaqMan Gene Expression Assays for RelA (Hs00153294_m1), Twist1 (Hs00361186_m1), full-length AR (Hs00171172_ $\mathrm{m} 1$ ), AR V7 (made to order), HIF-1 $\alpha$ (Hs00153153_m1), KLK3 (Hs00426859_g1), FKBP5 (Hs01561006_m1), PRKCE (Hs00942877_m1) and the glyceraldehyde 3-phosphate dehydrogenase gene (GAPDH; Hs02758991_g1) (Applied Biosystems) with TaqMan Gene Expression Master Mix (Applied Biosystems) with a 7900HT PCR system (Applied Biosystems). The transcript levels of the target genes were corrected according to the corresponding GAPDH transcript levels. All values represent the results of at least three independent experiments.

Published by Bioscientifica Ltd 


\section{Western blotting analysis}

Whole-cell extracts were prepared as described previously (Shiota et al. 2014a, 2016). Briefly, the concentrations of the prepared protein extracts were quantified using a protein assay (Bio-Rad) based on the Bradford method. Aliquots (30 $\mu$ g protein) were separated by $4-20 \%$ SDS-PAGE and transferred to polyvinylidene difluoride microporous membranes (GE Healthcare Bio-Science) using a semi-dry blotter. The membranes were then incubated with the primary antibodies described previously for $1 \mathrm{~h}$ at room temperature, followed by incubation with peroxidaseconjugated secondary antibodies for $40 \mathrm{~min}$ at room temperature. The bound antibodies were visualized using an ECL kit (GE Healthcare Bio-Science), and images were obtained using an image analyzer (Ez-Capture MG, ATTO, Tokyo, Japan).

\section{Luciferase reporter assay}

Prostate cancer cells $\left(2 \times 10^{5}\right)$ were co-transfected with $0.5 \mu \mathrm{g}$ of NF- $\mathrm{BB}$ reporter plasmid (pGL4.32(luc2P/ NF-kB-RE/Hygro), Promega), and $0.05 \mu \mathrm{g}$ of pRL-TK as an internal control with or without $40 \mathrm{nM}$ of the indicated siRNAs using Lipofectamine 2000. After $48 \mathrm{~h}$, the luciferase activities were detected using a Dual-Luciferase Reporter Assay System (Promega). The light intensities were measured using the ARVO MX plate reader. The firefly luciferase activities were corrected by the corresponding Renilla luciferase activities. The results are representative of at least three independent experiments.

\section{Statistical analysis}

All data were assessed using the Student $t$-test. All $P$ values are two sided. Levels of statistical significance were set at $P<0.05$.

\section{Results}

\section{Blocking PKC signaling suppresses RelA activity}

To explore the transcription factor responsible for Twist1 expression induced by PKC activation, we examined the known regulators of Twist1 transcription STAT3, HIF- $1 \alpha$ and NF-кB. PKCe regulating Twist1 expression (Shiota et al. 2014a) were silenced in LNCaP and 22Rv1 cells by specific siRNAs and checked phosphorylated STAT3 levels. However, PKC knockdown did not prominently suppress STAT3 phosphorylation in LNCaP and 22Rv1 cells (Supplementary Fig. 1A), whereas the PKC inhibitor Ro31-8220 suppressed phosphorylated STAT3 in 22Rv1 cells, but not in LNCaP cells (Supplementary Fig. 1B). Similarly, we investigated the involvement of HIF-1 $\alpha$. PKC inhibition using siRNA significantly reduced mRNA levels of their target genes (Supplementary Fig. 2A) and marginally decreased HIF- $1 \alpha$ mRNA and protein expression in both LNCaP and 22Rv1 cells (Supplementary Fig. 2B and C), whereas the PKC inhibitor Ro31-8220 significantly suppressed HIF- $1 \alpha$ at both mRNA and protein levels (Supplementary Fig. 2D and E). However, HIF-1 $\alpha$ knockdown did not suppress Twist1 or AR expression in LNCaP and 22Rv1 cells (Supplementary Fig. 3A and B). Taken together, these inconsistent results suggested that STAT3 and HIF-1 $\alpha$ were not robustly involved in Twist1/AR signaling as a downstream of PKC, at least in both LNCaP and 22Rv1 cells although there remains the possibility that these molecules may partially play a role in this pathway.

We subsequently examined the role of NF- $\mathrm{kB}$ in PKC/ Twist1 signaling to find out the robust molecule. The PKC inhibitor Ro31-8220 suppressed RelA expression at the transcriptional level in both LNCaP and 22Rv1 cells (Fig. 1A). Furthermore, Ro31-8220 suppressed the phosphorylation and protein expression of RelA in both LNCaP and 22Rv1 cells (Fig. 1B). We used siRNAs specific for PKCe to confirm that PKC regulates RelA. Although PKC knockdown did not affect RelA expression at the transcriptional level (Fig. 1C), PKCe knockdown suppressed RelA phosphorylation in LNCaP and 22Rv1 cells (Fig. 1D). In addition, reporter assay measuring NF-кB activity showed consistent results that the PKC inhibitor and PKC knockdown suppressed NF-kB activities (Fig. 1E).

\section{NF-KB regulates Twist1/AR signaling}

We investigated the effect of NF-кB on Twist1/AR signaling as a downstream of PKC by inhibiting RelA activation directly. When two kinds of RelA-specific siRNAs were utilized, RelA knockdown suppressed Twist1 and $A R$ mRNA expression in LNCaP cells and Twist1, full-length $A R$ and $A R$ V7 mRNA expression in 22Rv1 cells (Fig. 2A). RelA knockdown consistently suppressed Twist1 and fulllength AR expression at the protein level in LNCaP cells, whereas expression levels of Twist1, full-length AR and AR variants were affected by RelA knockdown in 22Rv1 cells, especially when RelA siRNA \#2 was utilized (Fig. 2B). 

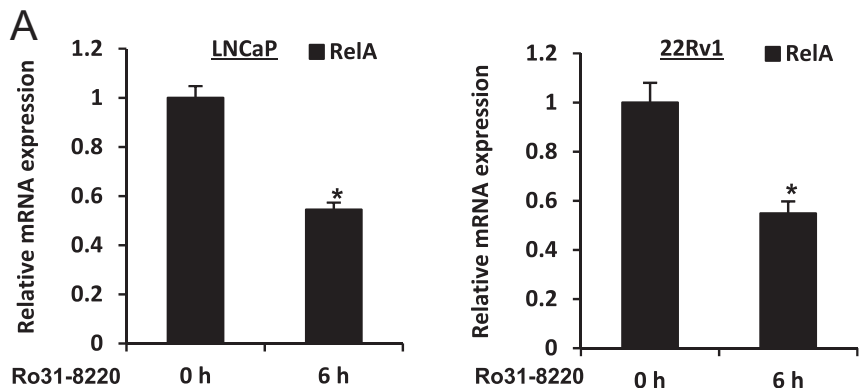

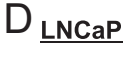

B
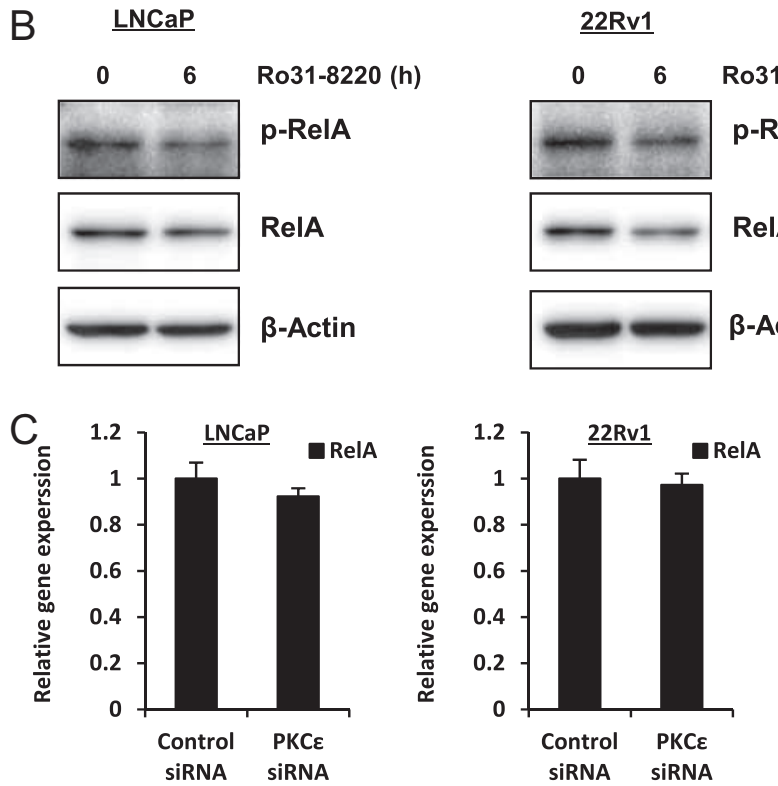
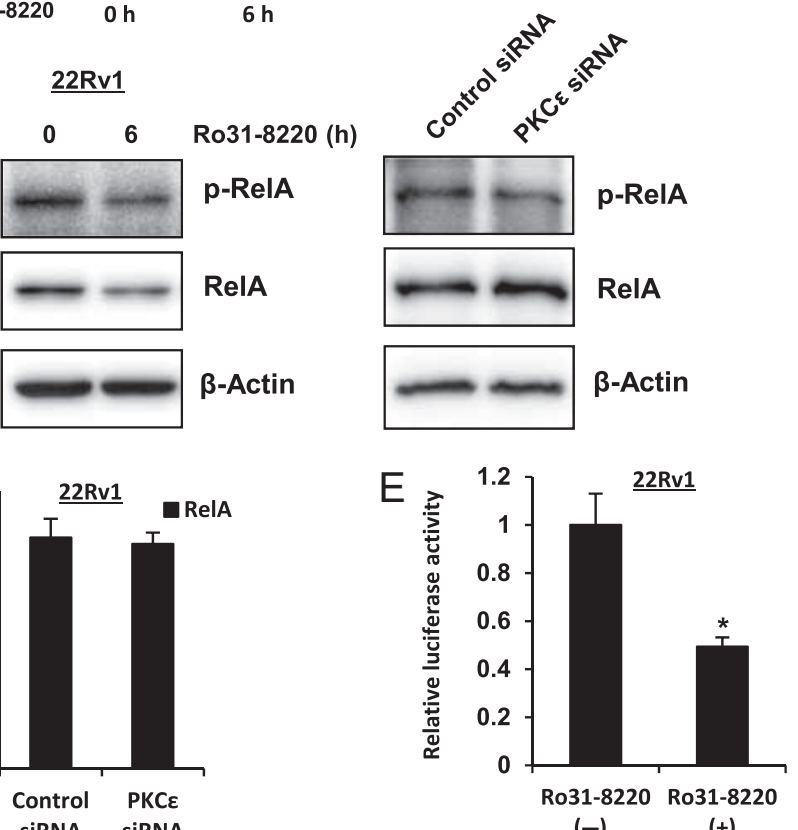

(+)
22Rv1
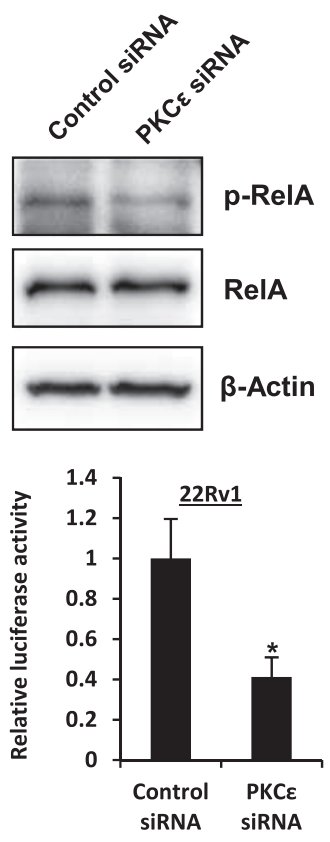

Figure 1

Blocking PKC signaling suppresses RelA activity. (A) LNCaP and 22Rv1 cells were incubated with 2.5 $\mu$ M Ro31-8220 for $6 \mathrm{~h}$. Quantitative real-time PCR was performed using the indicated primers and probes. The expression level of the target transcript was corrected according to the corresponding GAPDH transcript level. All values represent the results of at least three independent experiments. The level of each transcript in cells treated for $0 \mathrm{~h}$ was defined as 1. Boxes: mean; bars: \pm S.D. ${ }^{*} P<0.05$ (compared with $0 \mathrm{~h}$ ). (B) LNCaP and $22 \mathrm{Rv} 1$ cells were incubated with $2.5 \mu \mathrm{M}$ Ro31-8220 for $6 \mathrm{~h}$. Whole-cell extracts were subjected to SDS-PAGE, followed by Western blotting analyses of the indicated proteins. (C) LNCaP and $22 \mathrm{Rv} 1$ cells were transfected with $40 \mathrm{nM}$ of the indicated siRNA, and incubated for $48 \mathrm{~h}$. Quantitative real-time PCR was performed using the indicated primers and probes. The expression level of the target transcript was corrected according to the corresponding GAPDH transcript level. All values represent the results of at least three independent experiments. The level of each transcript in mock-transfected cells was defined as 1. Boxes: mean; bars: \pm S.D. ${ }^{*} P<0.05$ (compared with control siRNA). (D) LNCaP and 22Rv1 cells were transfected with $40 \mathrm{nM}$ of the indicated siRNA, and incubated for $72 \mathrm{~h}$. Whole-cell extracts were subjected to SDS-PAGE, followed by Western blotting analyses of the indicated proteins. (E) (Left panel) $22 \mathrm{Rv} 1$ cells were co-transfected with $0.5 \mu \mathrm{g}$ of $\mathrm{NF}-\kappa \mathrm{B}$ reporter plasmid and $0.05 \mu \mathrm{g}$ of pRL-TK, and incubated with or without $2.5 \mu \mathrm{M}$ of Ro31-8220 for $24 \mathrm{~h}$. (Right panel) $22 \mathrm{Rv} 1$ cells were co-transfected with $40 \mathrm{nM}$ of the indicated siRNA, $0.5 \mu \mathrm{g}$ of NF- $\mathrm{KB}$ reporter plasmid, and $0.05 \mu \mathrm{g}$ of pRL-TK. All values are representative of at least three independent experiments. The luciferase activity of the NF-KB reporter plasmid in LNCaP cells was set as 1 . Boxes: mean; bars: \pm s.D. ${ }^{\star} P<0.05$ (compared with non-treatment with Ro31-8220 and control siRNA).

\section{Blocking AR signaling induces PKC/RelA activation, resulting in Twist1/AR activation}

Given the previously mentioned results, we examined the effects of androgen depletion on PKC/RelA and Twist1/AR signaling. RelA mRNA expression was increased in LNCaP cells subjected to androgen depletion, but not in 22Rv1 cells (Fig. 3A). In addition, RelA phosphorylation was augmented by androgen depletion in LNCaP cells (Fig. 3B). We previously showed that PKC phosphorylation was augmented by androgen depletion, leading to the upregulation of Twist 1 and AR expression (Shiota et al. 2014a). Similarly, phosphorylation of PKC and RelA was increased by androgen depletion in 22Rv1 cells (Fig. 3B). Consistently, Twist1, full-length $A R$ and $A R V 7$ mRNA expression levels were increased by androgen deprivation in 22Rv1 cells (Fig. 3C). Furthermore, Twist1 and AR variant protein expression levels were markedly augmented by androgen depletion, whereas full-length AR protein expression was less augmented, possibly because of

Published by Bioscientifica Ltd. 
A
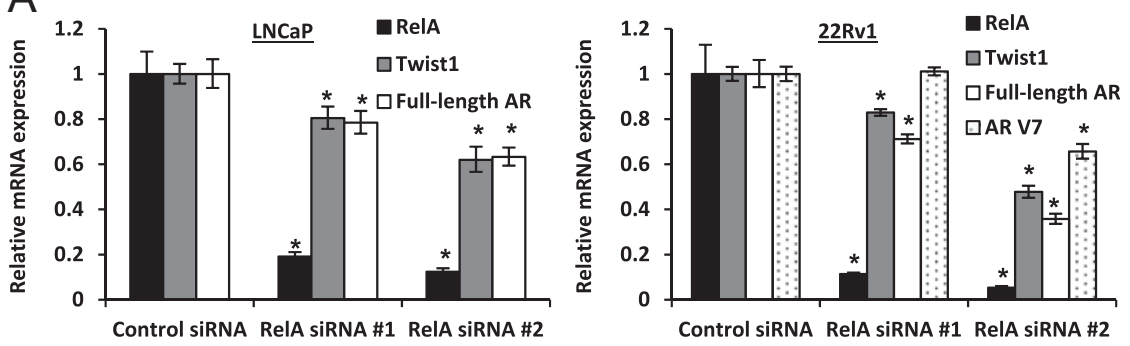

B

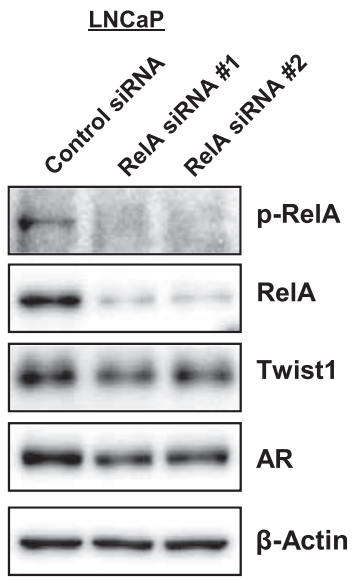

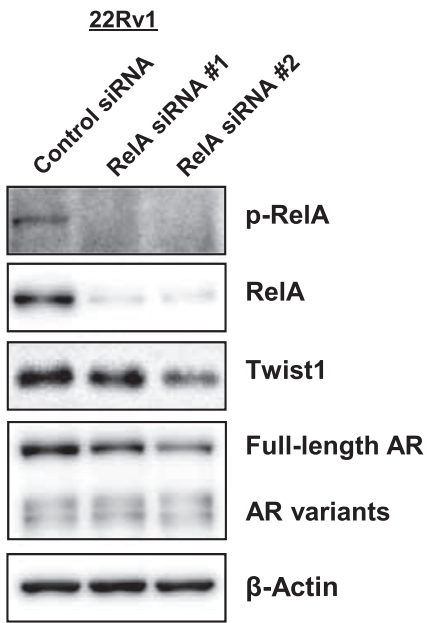

Figure 2

RelA regulates Twist1/AR signaling. (A) LNCaP and 22Rv1 cells were transfected with $40 \mathrm{nM}$ of the indicated siRNA, and incubated for $48 \mathrm{~h}$.

Quantitative real-time PCR was performed using the indicated primers and probes. The expression level of the target transcript was corrected according to the corresponding GAPDH transcript level. All values represent the results of at least three independent experiments. The level of each transcript in mock-transfected cells was defined as 1. Boxes: mean; bars: \pm s.D. ${ }^{*} P<0.05$ (compared with control siRNA). (B) LNCaP and 22Rv1 cells were transfected with $40 \mathrm{nM}$ of the indicated siRNA, and incubated for $72 \mathrm{~h}$. Whole-cell extracts were subjected to SDS-PAGE, followed by Western blotting analyses of the indicated proteins. increased protein degradation by lack of ligand binding under androgen depletion (Fig. 3D).

We also blocked AR signaling using enzalutamide, effects of which were confirmed by the suppression of AR target genes KLK3 and FKBP5 mRNA levels with enzalutamide (Supplementary Fig. 4B). Twist1 and $A R$ mRNA expression levels in LNCaP cells were increased by enzalutamide (Shiota et al. 2014a), whereas RelA mRNA expression was unaffected (Fig. 4A). Similarly, Twist1, fulllength $A R$ and $A R V 7$ mRNA levels in 22Rv1 cells were increased by enzalutamide, whereas RelA mRNA was not (Fig. 4B). RelA phosphorylation was also augmented in LNCaP cells (Fig. 4C), consistent with increased phosphorylation of PKC and increased Twist1 and AR expression, as previously shown (Shiota et al. 2014a). PKC phosphorylation and protein expression levels of RelA, Twist1 and AR variants were augmented by enzalutamide in 22Rv1 cells, whereas full-length AR protein expression was less augmented, possibly because of increased protein degradation by blocking of ligand binding by enzalutamide (Fig. 4D).

\section{Inhibition of NF- $\kappa$ B signaling prevents enzalutamide-induced Twist 1 and AR expressions}

To delineate the role of NF- $\kappa \mathrm{B}$ signaling in Twist1 and AR expression induced by blocking AR signaling, we examined
Twist1 and AR expression levels after enzalutamide treatment, with or without blocking NF- $\mathrm{BB}$ signaling, in castration-resistant 22Rv1 cells. RelA knockdown with enzalutamide suppressed RelA, Twist1 and full-length AR mRNA expression levels in 22Rv1 cells, whereas $A R V 7$ was little affected by RelA knockdown (Fig. 5A). This may be because AR V7 expression was induced by complementary pathways, such as the RSK/YB-1 pathway (Shiota et al. 2016). Similarly, RelA, Twist1 and full-length AR protein expression levels were reduced by RelA knockdown, whereas AR variant protein expression was little affected (Fig. 5B).

\section{NF- $\kappa$ B is activated in CRPC and enzalutamide-resistant cells}

To reveal the biological relevance of NF- $\mathrm{B}$ signaling, we examined the activation status of NF- $\kappa \mathrm{B}$ signaling in CRPC and enzalutamide-resistant prostate cancer cells. RelA mRNA expression and levels of phosphorylated RelA were augmented in castration-resistant CxR cells (Fig. 6A and B), as well as NF-кB activity indicated by reporter assay in castration-resistant 22Rv1 cells, compared with LNCaP cells (Supplementary Fig. 5A). Similarly, RelA mRNA expression and phosphorylated RelA were augmented in enzalutamide-resistant LNCaP/MDV and C4-2/MDV cells (Fig. 6C and D), where PKC activities appeared to be

Published by Bioscientifica Ltd. 

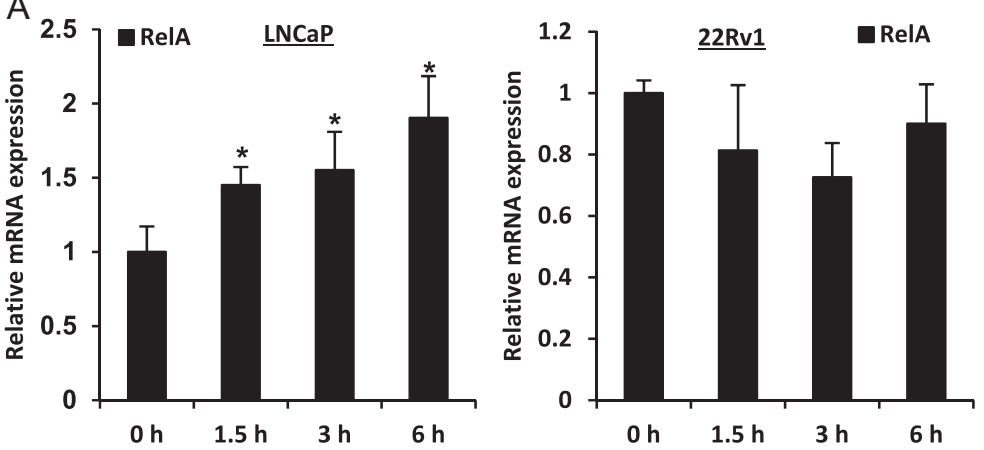

B

LNCaP

22Rv1
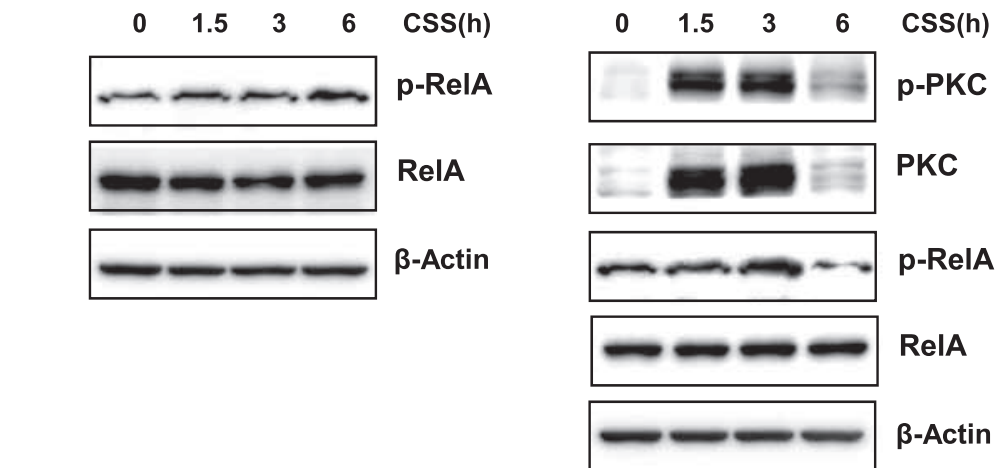

C

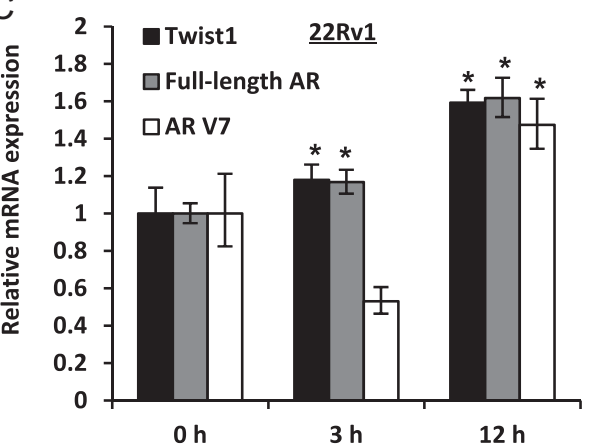

D 22Rv1

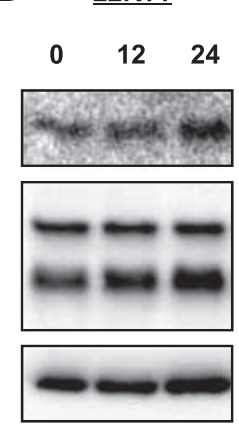

css (h)

Twist1

Full-length AR

AR variants

$\beta$-Actin

\section{Figure 3}

Androgen depletion induces PKC/RelA activation and Twist1/AR suppression. (A) and (C) LNCaP and $22 \mathrm{Rv} 1$ cells were incubated under media with $10 \%$ charcoal-stripped serum (CSS) for the indicated duration. Quantitative real-time PCR was performed using the indicated primers and probes. The expression level of the target transcript was corrected according to the corresponding GAPDH transcript level. All values represent the results of at least three independent experiments. The level of each transcript in cells treated for $0 \mathrm{~h}$ was defined as 1 . Boxes: mean; bars: \pm S.D. ${ }^{*} P<0.05$ (compared with $0 \mathrm{~h}$ ).

(B) and (D) LNCaP and 22Rv1 cells were incubated under media with $10 \%$ CSS for the indicated duration. Whole-cell extracts were subjected to SDS-PAGE, followed by Western blotting analyses of the indicated proteins. augmented in enzalutamide-resistant cells (Supplementary Fig. 5B). This finding was partially confirmed by reporter assay indicating higher NF- $\mathrm{kB}$ activity in C4-2/MDV cells compared with that in $\mathrm{C} 4-2$ cells (Fig. 6E).

\section{Discussion}

Previous studies showed that PKC/Twist1 signaling induced by AR-targeting therapy resulted in the development of CRPC via augmented AR expression (Shiota et al. 2010, 2014a). However, the mechanism of Twist1 induction by activated PKC remains unclear. In this study, we identified a role for the transcription factor NF-кB in Twist1 upregulation by activated PKC, whereas the other known Twist1 regulators STAT3 or HIF-1 $\alpha$ were not involved. In addition, NF-kB has previously been shown to regulate AR expression directly (Zhang et al. 2009), suggesting that NF- $\mathrm{KB}$ thus regulates AR expression directly as downstream of PKC.

RelA phosphorylation by various kinases at each phosphorylation site is required for optimal induction of NF- $\mathrm{kB}$ target genes in response to distinct stimuli (Viatour et al. 2005). RelA Ser536 may be phosphorylated by a variety of kinases, such as IкB kinases, TANK-binding kinase, Akt and ribosomal s6 kinase, via various signaling pathways (Viatour et al. 2005). However, no studies have demonstrated direct phosphorylation of RelA at Ser536 yet, though PKC has been shown to phosphorylate RelA at Ser311 (Duran et al. 2003). The results of the current study thus suggest that phosphorylation of RelA at Ser536 

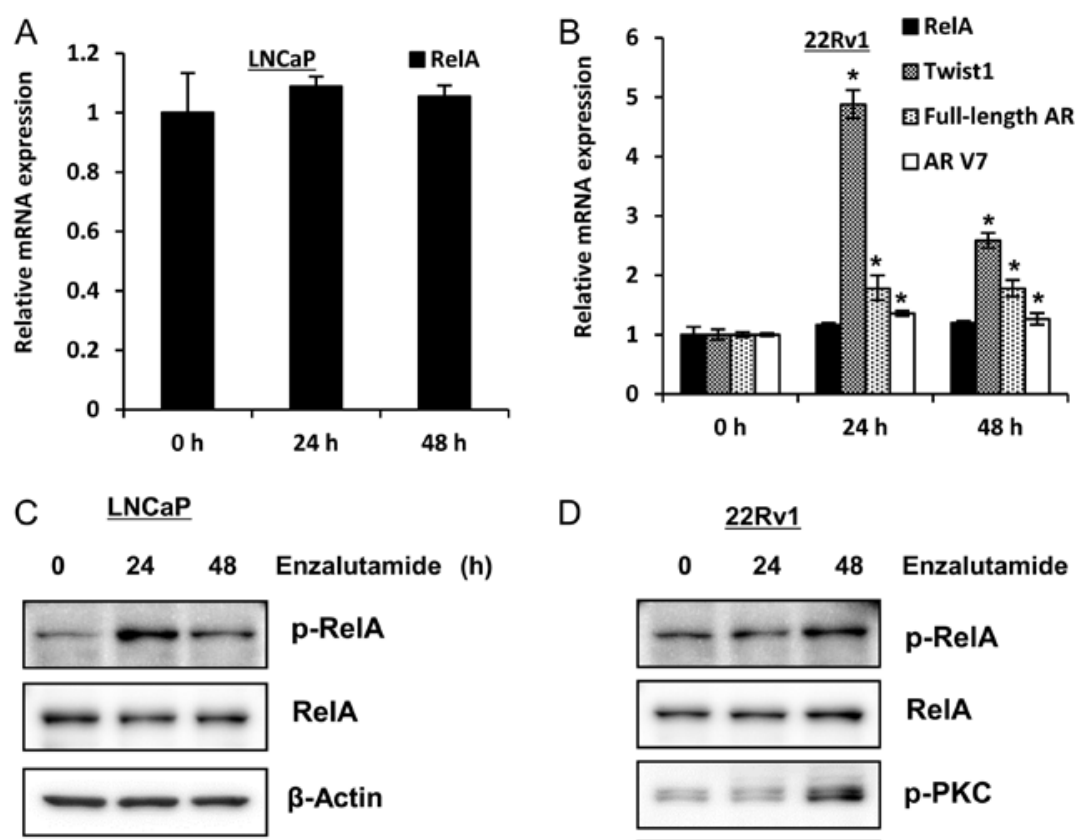

D

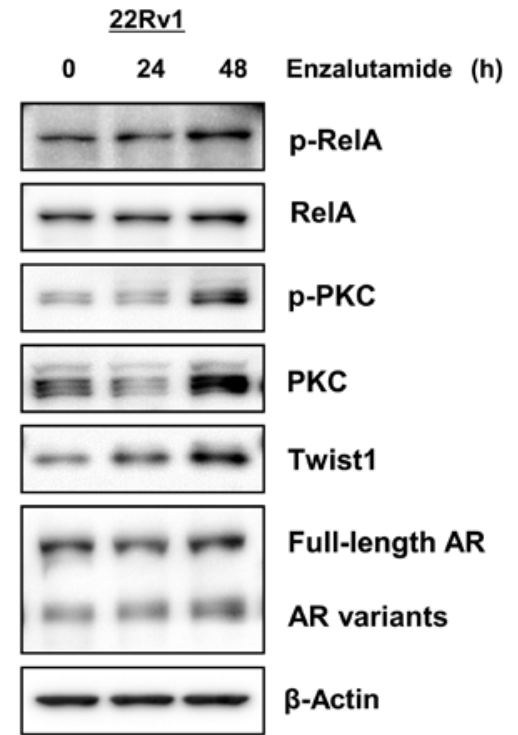

Figure 4

Enzalutamide induces PKC/RelA activation and Twist1/AR suppression. (A) and (B) LNCaP (A) and 22Rv1 (B) cells were incubated with $10 \mu \mathrm{M}$ enzalutamide for the indicated duration. Quantitative real-time PCR was performed using the indicated primers and probes. The expression level of the target transcript was corrected according to the corresponding GAPDH transcript level. All values represent the results of at least three independent experiments. The level of each transcript in cells treated for $0 \mathrm{~h}$ was defined as 1 . Boxes: mean; bars: \pm S.D. ${ }^{*} P<0.05$ (compared with $0 \mathrm{~h})$. (C) and (D) LNCaP (C) and 22Rv1 (D) cells were incubated with $10 \mu \mathrm{M}$ enzalutamide for the indicated duration. Whole-cell extracts were subjected to SDS-PAGE, followed by Western blotting analyses of the indicated proteins. may be affected directly or indirectly via PKCs. NF-кB was previously reported to be activated in response to androgen depletion in an LNCaP xenograft model (Chiu et al. 2010). Similarly, AR was shown to be a negative regulator of NF- $\kappa \mathrm{B}$ transcriptional activity (Palvimo et al. 1996, Cinar et al. 2004). Although the mechanism of NF-кB activation remains unclear, the present study consistently showed that NF-кB as well as enzalutamide was activated
A

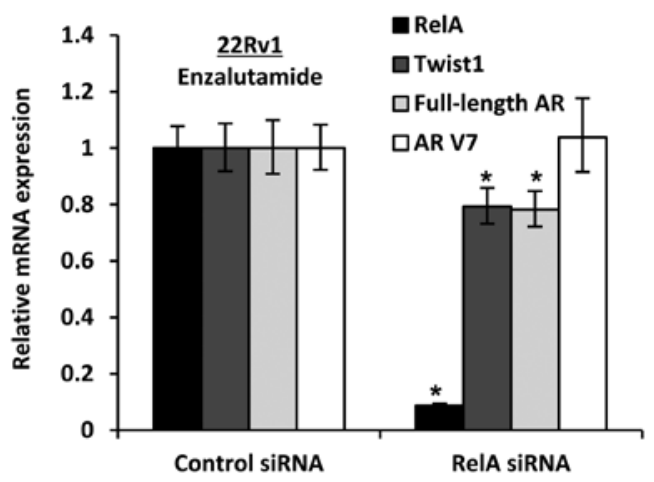

B $\quad \underline{22 R v 1}$ Enzalutamide

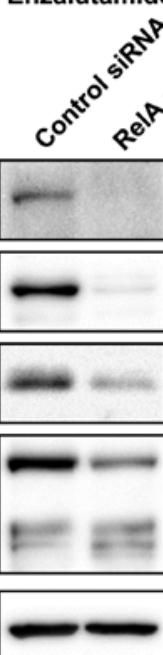

Figure 5

Inhibition of NF-KB signaling prevents enzalutamide-induced Twist 1 and AR expressions. (A) 22Rv1 cells were transfected with $40 \mathrm{nM}$ of control siRNA or RelA siRNA \#2, incubated for $24 \mathrm{~h}$, and were further incubated with $10 \mu \mathrm{M}$ enzalutamide for $24 \mathrm{~h}$. Quantitative real-time PCR was performed using the indicated primers and probes. The expression level of the target transcript was corrected according to the corresponding GAPDH transcript level. All values represent the results of at least three independent experiments. The level of each transcript in mock-transfected cells was defined as 1. Boxes: mean; bars: \pm S.D. ${ }^{*} P<0.05$ (compared with control siRNA). (B) 22Rv1 cells were transfected with $40 \mathrm{nM}$ of control siRNA or RelA siRNA \#2, incubated for $24 \mathrm{~h}$, and were further incubated with $10 \mu \mathrm{M}$ enzalutamide for $48 \mathrm{~h}$. Whole-cell extracts were subjected to SDS-PAGE, followed by Western blotting analyses of the indicated proteins. 


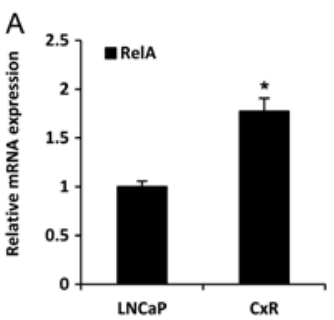

B

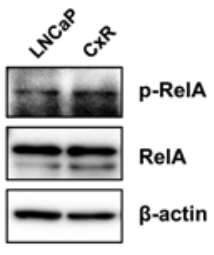

C
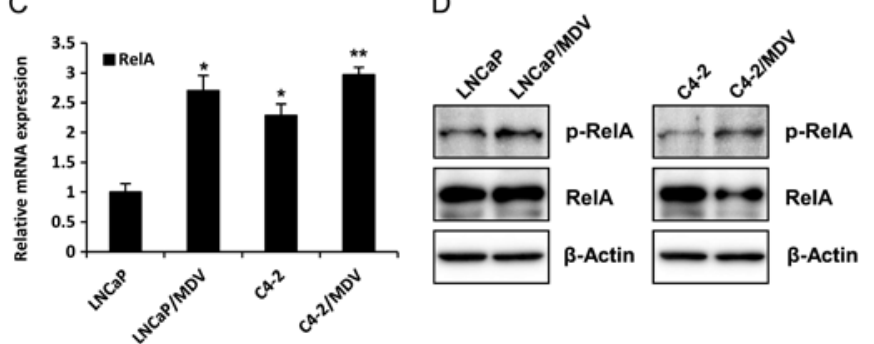
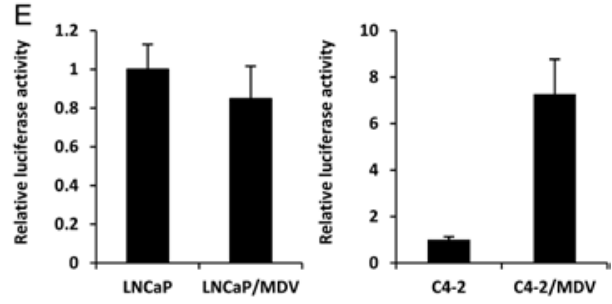

Figure 6

NF-KB is activated in CRPC and in enzalutamide-resistant cells. (A) After extraction of total RNA from LNCaP and CxR cells and synthesis of cDNA, quantitative real-time PCR was performed using the indicated primers and probes. The expression level of the target transcript was corrected according to the corresponding GAPDH transcript level. All values represent the results of at least three independent experiments. The level of each transcript in LNCaP cells was defined as 1. Boxes: mean; bars: \pm s.D. ${ }^{*} P<0.05$ (compared with LNCaP cells). (B) Whole-cell extracts from LNCaP and CxR cells were subjected to SDS-PAGE, followed by Western blotting analyses of the indicated proteins. (C) After extraction of total RNA from LNCaP, LNCaP/MDV, C4-2 and C4-2/MDV cells and synthesis of CDNA, quantitative real-time PCR was performed using the indicated primers and probes. The expression level of the target transcript was corrected according to the corresponding GAPDH transcript level. All values represent the results of at least three independent experiments. The level of each transcript in LNCaP cells was defined as 1 . Boxes: mean; bars: \pm s.D. * $P<0.05$ (compared with LNCaP cells). ${ }^{*} P<0.05$ (compared with C4-2 cells). (D) Whole-cell extracts from LNCaP, LNCaP/MDV, C4-2 and C4-2/MDV cells were subjected to SDS-PAGE, followed by Western blotting analyses of the indicated proteins. (E) LNCaP, LNCaP/MDV, C4-2 and C4-2/MDV cells were co-transfected with 0.5 $\mu$ g of NF-KB reporter plasmid and $0.05 \mu \mathrm{g}$ of $\mathrm{pRL}-\mathrm{TK}$. All values are representative of at least three independent experiments. The luciferase activity of the NF- $\mathrm{KB}$ reporter plasmid in LNCaP and C4-2 cells was set as 1 . Boxes: mean; bars: \pm S.D. ${ }^{*} P<0.05$ (compared with LNCaP and C4-2 cells).

in response to castration. Overall, these results suggest that PKC is involved in NF- $\mathrm{BB}$ activation by AR blocking through RelA phosphorylation. In addition, we have previously reported that TGF- $\beta$ signaling also regulated Twist1 expression in 22Rv1 cells, but not in LNCaP cells (Shiota et al. 2012b). PKC acts with TGF- $\beta$ receptor to promote epithelial-to-mesenchymal transition (Gonzalez $\&$ Medici 2014). Then, in 22Rv1 cells, PKC may co-operate Twist1/AR signaling with TGF- $\beta$ signaling.

NF- $\mathrm{B}$ induces cell proliferation and anti-apoptotic gene expression and also enhances angiogenesis via VEGF expression in response to pro-inflammatory cytokines. Accordingly, NF- $\mathrm{kB}$ activity has been reported to be a hallmark of cancer, including prostate cancer (Nguyen et al. 2014). In addition, activation of NF-кB signaling was correlated with poor prognosis and was upregulated in patients with CRPC (McCall et al. 2012). RelA activity may thus have a diagnostic relevance in prostate cancer. There are three distinct NF-кB-activating pathways: the classical and alternative pathways utilize RelA/p50 or c-Rel/p50 heterodimers, whereas the atypical pathway utilizes the RelB/p52 heterodimer as NF- $\kappa$ B1 and

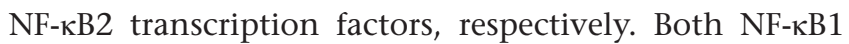

(Jin et al. 2015) and NF-kB2 (Nadiminty et al. 2013) pathways were previously reported to be involved in AR variant expression, as well as in castration resistance and enzalutamide resistance. NF- $\mathrm{B}$ thus appears to be a promising therapeutic target in the PKC/Twist1 pathway. Actually, several compounds inhibiting NF- $\mathrm{B}$ signaling have been developing in pre-clinical studies (Lee et al. 2007), and some of them are now under clinical trials for hematological malignancies (Fuchs 2010). Therefore, it would be intriguing to examine the therapeutic effect of NF-кB inhibitors on castration-resistant and enzalutamide-resistant prostate cancer.

In conclusion, NF- $\mathrm{B}$ signaling is responsible for Twist1 upregulation by PKC in response to AR inhibition, resulting in the aberrant activation of AR. NF- $\kappa \mathrm{B}$ signaling thus appears to be an important factor promoting castration resistance, as well as enzalutamide resistance in PKC/Twist1 signaling in prostate cancer.

\section{Supplementary data}

This is linked to the online version of the paper at http://dx.doi.org/10.1530/ ERC-16-0384.

Published by Bioscientifica Ltd. 


\section{Declaration of interest}

Masaki Shiota, Akira Yokomizo and Masatoshi Eto have received honoraria from Astellas Pharma.

\section{Funding}

This work was supported by a Medical Research Promotion Grant from Takeda Science Foundation, a Research Promotion Grant from Daiwa Securities Health Foundation and a Research Promotion Grant from the Smoking Research Foundation.

\section{Acknowledgements}

The authors are grateful to Dr Martin Gleave (Vancouver Prostate Centre, Vancouver, BC, Canada) for providing C4-2 cells. The author would also like to thank Edanz Group Japan for editorial assistance, and Noriko Hakoda and Eriko Gunshima for technical assistance.

\section{References}

Cai C \& Balk SP 2011 Intratumoral androgen biosynthesis in prostate cancer pathogenesis and response to therapy. Endocrine-Related Cancer 18 R175-R182. (doi:10.1530/ERC-10-0339)

Cheng GZ, Zhang WZ, Sun M, Wang Q, Coppola D, Mansour M, $\mathrm{Xu}$ LM, Costanzo C, Cheng JQ \& Wang LH 2008 Twist is transcriptionally induced by activation of STAT3 and mediates STAT3 oncogenic function. Journal of Biological Chemistry 283 14665-14673. (doi:10.1074/jbc.M707429200)

Chiu HH, Yong TM, Wang J, Wang Y, Vessella RL, Ueda T, Wang YZ \& Sadar MD 2010 Induction of neuronal apoptosis inhibitory protein expression in response to androgen deprivation in prostate cancer. Cancer Letters 292 176-185. (doi:10.1016/j.canlet.2009.11.023)

Cinar B, Yeung F, Konaka H, Mayo MW, Freeman MR, Zhau HE \& Chung LW 2004 Identification of a negative regulatory cis-element in the enhancer core region of the prostate-specific antigen promoter: implications for intersection of androgen receptor and nuclear factor- $\mathrm{kB}$ signalling in prostate cancer cells. Biochemical Journal 379 421-431. (doi:10.1042/bj20031661)

de Bono JS, Logothetis CJ, Molina A, Fizazi K, North S, Chu L, Chi KN, Jones RJ, Goodman OB Jr, Saad F, et al. 2011 Abiraterone and increased survival in metastatic prostate cancer. New England Journal of Medicine 364 1995-2005. (doi:10.1056/NEJMoa1014618)

Duran A, Diaz-Meco MT \& Moscat J 2003 Essential role of RelA Ser311

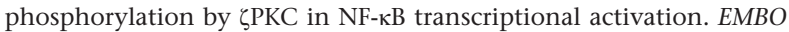
Journal 22 3910-3918. (doi:10.1093/emboj/cdg370)

Fuchs O 2010 Transcription factor NF-кB inhibitors as single therapeutic agents or in combination with classical chemotherapeutic agents for the treatment of hematologic malignancies. Current Molecular Pharmacology 3 98-122. (doi:10.217 4/1874467211003030098)

Gonzalez DM \& Medici D 2014 Signaling mechanisms of the epithelialmesenchymal transition. Science Signaling 7 re8. (doi:10.1126/ scisignal.2005189)

Inoue T \& Ogawa O 2011 Role of signaling transduction pathways in development of castration-resistant prostate cancer. Prostate Cancer 2011 647987. (doi:10.1155/2011/647987)

Inoue T, Yoshida T, Shimizu Y, Kobayashi T, Yamasaki T, Toda Y, Segawa T, Kamoto T, Nakamura E \& Ogawa O 2006 Requirement of androgen-dependent activation of protein kinase $C \zeta$ for androgendependent cell proliferation in LNCaP cells and its roles in transition to androgen-independent cells. Molecular Endocrinology 20 3053-3069. (doi:10.1210/me.2006-0033)
Jin R, Yamashita H, Yu X, Wang J, Franco OE, Wang Y, Hayward SW \& Matusik RJ 2015 Inhibition of NF-кB signaling restores responsiveness of castrate-resistant prostate cancer cells to antiandrogen treatment by decreasing androgen receptor-variant expression. Oncogene 34 3700-3710. (doi:10.1038/onc.2014.302)

Lamoureux F, Thomas C, Yin MJ, Kuruma H, Beraldi E, Fazli L, Zoubeidi A \& Gleave ME 2011 Clusterin inhibition using OGX-011 synergistically enhances Hsp90 inhibitor activity by suppressing the heat shock response in castrate-resistant prostate cancer. Cancer Research 71 5838-5849. (doi:10.1158/0008-5472.CAN-11-0994)

Lee CH, Jeon YT, Kim SH \& Song YS 2007 NF-кB as a potential molecular target for cancer therapy. Biofactors 29 19-35. (doi:10.1002/biof.5520290103)

Lo HW, Hsu SC, Xia W, Cao X, Shih JY, Wei Y, Abbruzzese JL, Hortobagyi GN \& Hung MC 2007 Epidermal growth factor receptor cooperates with signal transducer and activator of transcription 3 to induce epithelial-mesenchymal transition in cancer cells via up-regulation of TWIST gene expression. Cancer Research $\mathbf{6 7}$ 9066-9076. (doi:10.1158/0008-5472.CAN-07-0575)

McCall P, Bennett L, Ahmad I, Mackenzie LM, Forbes IW, Leung HY, Sansom OJ, Orange C, Seywright M, Underwood MA, et al. 2012 $\mathrm{NF} \kappa \mathrm{B}$ signalling is upregulated in a subset of castrate-resistant prostate cancer patients and correlates with disease progression. British Journal of Cancer 107 1554-1563. (doi:10.1038/bjc.2012.372)

Nadiminty N, Tummala R, Liu C, Yang J, Lou W, Evans CP \& Gao AC 2013 NF-кB2/p52 induces resistance to enzalutamide in prostate cancer: role of androgen receptor and its variants. Molecular Cancer Therapeutics 12 1629-1637. (doi:10.1158/1535-7163.MCT-13-0027)

Nguyen DP, Li J, Yadav SS \& Tewari AK 2014 Recent insights into NF-кB signalling pathways and the link between inflammation and prostate cancer. BJU International 114 168-176. (doi:10.1111/bju.12488)

Palvimo JJ, Reinikainen P, Ikonen T, Kallio PJ, Moilanen A \& Jänne OA 1996 Mutual transcriptional interference between RelA and androgen receptor. Journal of Biological Chemistry $27124151-24156$. (doi:10.1074/jbc.271.39.24151)

Pham CG, Bubici C, Zazzeroni F, Knabb JR, Papa S, Kuntzen C \& Franzoso G 2007 Upregulation of Twist-1 by NF-кB blocks cytotoxicity induced by chemotherapeutic drugs. Molecular and Cellular Biology 27 3920-3935. (doi:10.1128/MCB.01219-06)

Ryan CJ \& Tindall DJ 2011 Androgen receptor rediscovered: the new biology and targeting the androgen receptor therapeutically. Journal of Clinical Oncology 29 3651-3658. (doi:10.1200/JCO.2011.35.2005)

Ryan CJ, Smith MR, de Bono JS, Molina A, Logothetis CJ, de Souza P, Fizazi K, Mainwaring P, Piulats JM, Ng S, et al. 2013 Abiraterone in metastatic prostate cancer without previous chemotherapy. New England Journal of Medicine 368 138-148. (doi:10.1056/ NEJMoa1209096)

Sadar MD 2011 Small molecule inhibitors targeting the 'achilles' heel' of androgen receptor activity. Cancer Research 71 1208-1213. (doi:10.1158/0008-5472.CAN 10-3398)

Scher HI, Fizazi K, Saad F, Taplin ME, Sternberg CN, Miller K, de Wit R, Mulders P, Chi KN, Shore ND, et al. 2012 Increased survival with enzalutamide in prostate cancer after chemotherapy. New England Journal of Medicine 367 1187-1197. (doi:10.1056/NEJMoa1207506)

Sharifi N, Gulley JL \& Dahut WL 2010 An update on androgen deprivation therapy for prostate cancer. Endocrine-Related Cancer $\mathbf{1 7}$ R305-R315. (doi:10.1677/ERC-10-0187)

Shiota M, Izumi H, Onitsuka T, Miyamoto N, Kashiwagi E, Kidani A, Yokomizo A, Naito S \& Kohno K 2008 Twist promotes tumor cell growth through YB-1 expression. Cancer Research 68 98-105. (doi:10.1158/0008-5472.CAN-07-2981)

Shiota M, Yokomizo A, Tada Y, Inokuchi J, Kashiwagi E, Masubuchi D, Eto M, Uchiumi T \& Naito S 2010 Castration resistance of prostate cancer cells caused by castration-induced oxidative stress through Twist1 and androgen receptor overexpression. Oncogene 29 237-250. (doi:10.1038/onc.2009.322) 
Shiota M, Yokomizo A, Fujimoto N \& Naito S 2011a Androgen receptor cofactors in prostate cancer: potential therapeutic targets of castration-resistant prostate cancer. Current Cancer Drug Targets 11 870-881. (doi:10.2174/156800911796798904)

Shiota M, Yokomizo A \& Naito S $2011 b$ Increased androgen receptor transcription: a cause of castration-resistant prostate cancer and a possible therapeutic target. Journal of Molecular Endocrinology 47 R25-R41. (doi:10.1530/JME-11-0018)

Shiota M, Song Y, Takeuchi A, Yokomizo A, Kashiwagi E, Kuroiwa K, Tatsugami K, Uchiumi T, Oda Y \& Naito S 2012a Antioxidant therapy alleviates oxidative stress by androgen deprivation and prevents conversion from androgen dependent to castration resistant prostate cancer. Journal of Urology 187 707-714. (doi:10.1016/j. juro.2011.09.147)

Shiota M, Zardan A, Takeuchi A, Kumano M, Beraldi E, Naito S, Zoubeidi A \& Gleave ME $2012 b$ Clusterin mediates TGF- $\beta$-induced epithelial-mesenchymal transition and metastasis via Twist1 in prostate cancer cells. Cancer Research 72 5261-5272. (doi:10.1158/0008-5472.CAN-12-0254)

Shiota M, Yokomizo A, Takeuchi A, Imada K, Kashiwagi E, Song Y, Inokuchi J, Tatsugami K, Uchiumi T \& Naito S 2014a Inhibition of protein kinase C/Twist1 signaling augments anticancer effects of androgen deprivation and enzalutamide in prostate cancer. Clinical Cancer Research 20 951-961. (doi:10.1158/1078-0432.CCR-13-1809)

Shiota M, Yokomizo A, Takeuchi A, Itsumi M, Imada K, Kashiwagi E, Inokuchi J, Tatsugami K, Uchiumi T \& Naito S 2014b Inhibition of
RSK/YB-1 signaling enhances the anti-cancer effect of enzalutamide in prostate cancer. Prostate 74 959-969. (doi:10.1002/pros.22813)

Shiota M, Fujimoto N, Imada K, Yokomizo A, Itsumi M, Takeuchi A, Kuruma H, Inokuchi J, Tatsugami K, Uchiumi T, et al. 2016 Potential role for YB-1 in castration-resistant prostate cancer and resistance to enzalutamide through the androgen receptor V7. Journal of National Cancer Institute 108 djw005. (doi:10.1093/jnci/djw005)

Sun Y, Wang BE, Leong KG, Yue P, Li L, Jhunjhunwala S, Chen D, Seo K, Modrusan Z, Gao WQ, et al. 2012 Androgen deprivation causes epithelial-mesenchymal transition in the prostate: implications for androgen-deprivation therapy. Cancer Research 72 527-536. (doi:10.1158/0008-5472.CAN-11-3004)

Viatour P, Merville MP, Bours V \& Chariot A 2005 Phosphorylation of

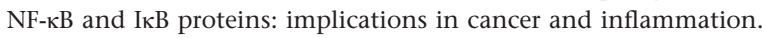
Trends in Biochemical Sciences 30 43-52. (doi:10.1016/j. tibs.2004.11.009)

Waltering KK, Urbanucci A \& Visakorpi T 2012 Androgen receptor (AR) aberrations in castration-resistant prostate cancer. Molecular and Cellular Endocrinology 360 38-43. (doi:10.1016/j.mce.2011.12.019)

Yang MH, Wu MZ, Chiou SH, Chen PM, Chang SY, Liu CJ, Teng SC \& Wu KJ 2008 Direct regulation of TWIST by HIF-1 $\alpha$ promotes metastasis. Nature Cell Biology 10 295-305. (doi:10.1038/ncb1691)

Zhang L, Altuwaiji A, Deng F, Chen L, Lal P, Bhanot UK, Korets R, Wenske S, Lilja HG, Chang C, et al. 2009 NF- $\kappa$ B regulates androgen receptor expression and prostate cancer growth. American Journal of Pathology 175 489-499. (doi:10.2353/ajpath.2009.080727)

Received in final form 7 February 2017

Accepted 21 February 2017

Accepted Preprint published online 21 February 2017
(C) 2017 Society for Endocrinology Printed in Great Britain
Published by Bioscientifica Ltd. 